\title{
MC-1 ENGINE VALVES, LESSONS LEARNED
}

\author{
John Laszar, Engineer, Space Transportation Directorate, \\ Marshall Space Flight Center, Huntsville, Alabama;
}

\begin{abstract}
$\underline{\text { Abstract }}$
Many lessons were learned during the development of the valves for the MC-1 engine. The purpose of this report is to focus on a variety of issues related to the engine valves and convey the lessons learned. This paper will not delve into detailed technical analysis of the components. None of the lessons learned are new or surprising, but simply reinforce the importance of addressing the details of the design early, at the component level. The Marshall Space Flight Center (MSFC), Huntsville, Alabama developed the MC-1 engine, a LOX / RP-1, 60,000 pound thrust engine. This engine was developed under the Low Cost Boost Technology office at MSFC and proved to be a very successful project for the MSFC Propulsion team and the various subcontractors working the development of the engine and its components.
\end{abstract}

\section{Design Philosophy and Background}

Historically, rocket engine valves have been a significant percentage of the cost of an engine. One objective of the MC-1 engine was to reduce engine cost by an order of magnitude. The solution proposed to the valve designer was to use commercial-off-the-shelf (COTS) valves. Unfortunately, because of the extreme environments and stringent requirements typical of rocket engines, COTS valves do not exist. The purge control valves could approach the concept of COTS, but these valves are by no means "off-the-shelf". Many aerospace valve suppliers were solicited to participate in the MC-1 development, including suppliers with commercial aircraft valve experience and little or no experience with rocket valve technology. There were no COTS valves identified that could meet the MC-1 requirements. There was also pressure to use "facility" valves to reduce cost. It was concluded that the flight requirements would drive the "facility" valves toward "flight" type valves in terms of design and as a result, cost and schedule. Another solution proposed to the valve designer was to combine functions required of the valves. Again, because of cost and schedule, combination of valve functions was limited in order to maintain a conventional valve design, and therefore minimize valve development.

Procurement specifications were generated for the Main Oxidizer Valve (MOV), Main Fuel Valve (MFV), Gas Generator Oxidizer Valve (GGOV), Gas Generator
Fuel Valve (GGFV), Oxidizer Bleed Valve (OBV), Fuel Bleed Valve (FBV), Ignition Fuel Valve (IFV), Main Fuel Purge Valve (MFPV), Oxidizer Purge Valve (OPV), and Gas Generator LOX Purge Valve (GLPV) prior to the development of an engine specification. The specifications were written to allow the suppliers to use their existing designs, specifications, and standards to the maximum extent. The MOV, MFV, GGOV, GGFV, OBV, and FBV were competed as a mid-range, firm fixed price procurement.

The MFPV, OPV, GLPV, and IFV requirements were met by existing valve designs that had been used extensively on test stands and flight vehicles. A sole source justification was accepted to procure the MFPV, OPV, GLPV, and IFV.

The check valves were existing designs and were ordered as catalog valves. These check valves are used extensively in aerospace applications and some certification data was already available.

Because of the short schedule and tight budget, it was agreed that some of the valve development testing, normally performed, would be eliminated. It was understood that some problems would occur as a result of this decision and that those problems would be worked during engine development.

Before the discussion of the valve problems, it should be specifically stated that the performance and support provided by the valve suppliers during the MC-1 program was excellent. The many long and late hours contributed to the development of these valves, by many individuals, are greatly appreciated and will not be forgotten.

\section{Valve Description}

\section{MOV and MFV}

The MOV and MFV were proposed as identical valves to take full advantage of hardware commonality. The valves are normally closed, pneumatically actuated, 2.6-inch full port ball valves. The actuator is springloaded in the closed position and controlled with a three-way, two-position pilot valve that is mounted on the actuator body. The pilot valve was supplied to the vendor by a sub vendor. 
The design of the valve was a derivative of the RL10 Oxidizer Inlet Valve (OIV). The MC-1 operating pressures were significantly higher than the OIV pressures. Some changes were made to accommodate the higher pressures. The ball seal is a Teflon jacket, spring and pressure-energized seal and is an upstream seal. The valve has a primary and secondary shaft seal with a vent port in between. The shaft seal is a formed Kapton seal. Static seals are Teflon jacket, spring and pressure-energized seals.

The actuator is a spring-loaded piston that rotates the ball shaft through a linkage assembly. The piston seal is also a Teflon spring and pressure-energized seal. The pilot valve controls Helium pressure to the piston. Orifices are installed on the inlet and vent port of the pilot valve to control the pressurization rate and therefore the opening and closing times. A paddle that is attached to the actuator shaft activates separate open and closed position indication switches. The position indicators are hermetic switches.

The pilot valve is a three-way, two-position, direct acting solenoid valve. The seats are Vespel. A pushrod attached to the solenoid armature allows a ball to seat on either the inlet or vent seat. The pilot valve was a cartridge valve that is installed into the supplier's manifold. The pilot valve has been used extensively in applications where the temperature was $-65 \mathrm{~F}$ to $150 \mathrm{~F}$. The predicted temperatures on the cryogenic valves were as low as $-80 \mathrm{~F}$. The fuel valve pilot valves used elastomer o-rings. The elastomer seals were replaced with Teflon spring and pressure-energized seals for the oxidizer valves.

\section{GGOV, GGFV, and OBV}

The GGOV, GGFV, and OBV were proposed as identical valves to take full advantage of hardware commonality. The valves are normally closed, pneumatically actuated, poppet valves. The main seal is a Teflon jacket, spring and pressure-energized seal. An inlet bellows assembly and outlet bellows assembly serves as the shaft seals. At the closed position the bellows are at their free length. A compression spring, which is part of the outlet bellows assembly, provides seating force. The effective area of the bellows is slightly larger than the effective area of the seat, such that inlet pressure increases the seat load. Paddles on the end of the poppet assembly activate position switches. The position switches are identical to those used on the MOV and MFV.

The inlet bellows also acts as the actuation mechanism. Actuation pressure to the inlet bellows is controlled with a three-way, two-position pilot valve that is mounted on the valve body. The pilot valves are identical to those used on the MOV and MFV.

\section{$\underline{\text { FBV }}$}

The FBV is a normally closed, two-way, two-position direct-acting solenoid valve. The valve was an existing design with position indication added. The valve has been used extensively on flight vehicles and facility systems. The seats are Vespel. The stem seals and other soft goods are Viton. There are primary and secondary stem seals on the solenoid end of the poppet with a weep hole in the valve body.

\section{$\underline{\text { IFV }}$}

The IFV is a normally closed, two-way, two-position direct-acting solenoid valve. Valve development testing revealed that the original valve could not meet the flow capacity requirement and was modified to accommodate a solenoid with greater pull-in force. The body and poppet were also redesigned. The IFV also has position indication. The position switch is identical to the FBV position switch. The seats are Vespel. The stem seals and other soft goods are Buna-N. There are primary and secondary stem seals on the solenoid end of the poppet with a weep hole in the valve body.

\section{$\underline{\text { MFPV }}$}

The MFPV is a normally closed, internally piloted three-way, two-position valve. The pilot valve is a three-way, two-position direct-acting solenoid valve. The seats are Vespel and Kel-F. The stem seals and other soft goods are EPR and Buna-N. The vent of the pilot valve is ported through the valve body to a hole with a screen installed.

\section{OPV}

The OPV is a normally open, three-way, two-position direct-acting solenoid valve. The seats are vespel. The stem seals and other soft goods are Butyl and Fluorosilicone. There are primary and secondary stem seals on the solenoid end of the poppet with a weep hole in the valve body.

\section{GLPV}

The GLPV is a normally closed, three-way, twoposition direct-acting solenoid valve. The seats are Vespel. The stem seals and other soft goods are EPR and Buna- N. There are primary and secondary stem seals on the solenoid end of the poppet with a weep hole in the valve body. 


\section{Check Valves}

The check valves are all catalog items. The check valve design incorporates a floating o-ring. The spring is completely removed from the flow path; however the floating o-ring may be in the flow path. Because the floating o-ring may be in the flow path, there was concern that fluid force could roll an elastomer o-ring off of the poppet. This concern was the primary reason that Teflon o-rings were used in the fuel system as well as in the oxidizer system.

When the engine is installed in vertical configuration, a check valve was installed as a pump inlet high point bleed valve. This valve was originally made for an application with operating pressure of 225 psig. However, the supplier provided a letter stating that the valve could operate at the MC-1 operating pressure levels, as the components were designed for 3000 psi. In addition, the valves were proof pressure tested to MC-1 requirements to verify structural integrity.

\section{Design Evolution}

During development of the valves, a number of problems were encountered. Some problems occurred early in the development, some late in the engine test program. The following sections will address the significant problems and resulting changes, by issue and in somewhat chronological order.

\section{Nonlinear Slew Rate of MOV and MFV}

During valve development testing, the MOV and MFV actuation, or position vs. time plots, showed some nonlinearity. Engine system performance analysis indicated that the observed non-linearity would result in unacceptable pump cavitation and pressure oscillations during start and shutdown.

The non-linearity was caused primarily by stiction between the ball and ball seal. On open command, the pilot valve opens, sending gas to the actuator. Pressure in the actuator increases until the actuator force overcomes the breakaway friction. Then two events occur. The friction force between the ball shaft and seals decreases instantly because of the difference between breakaway and running friction. And as the ball shaft rotates open, the ball seal "falls" into the port, leaving only part of the seal circumference supported by the ball. As a result, the ball seal deforms, decreasing the seal load on the ball and therefore decreasing the friction between the ball seal and ball. Because of the sudden decrease in friction, and because the actuation medium is a compressible gas, the valve would "snap" partially open instantly, hold that position, then ramp open in a fairly linear response.

Several solutions were considered. Because of schedule pressure, the solution that required the least change impact was implemented. The decision was made to install a commercially available, rotary viscous damper with thermal compensation. The supplier of the damper provided test data showing effective thermal compensation to $-20 \mathrm{~F}$. Component bench testing performed on valves with the damper installed showed good linear response and no problem associated with nonlinear response was reported during engine testing.

Following the addition of the damper, some verification was repeated. A baseline actuation test was performed. Then the endurance and vibration tests were performed, followed by actuation testing. The testing was successfully completed with no shift in response time or any damage to hardware.

\section{Vent Line Isolation}

Originally the actuator vent lines were routed to a common drain line so that one line each, for fuel and LOX, would carry all fluids outside of the aft compartment. The LOX valve drain line was provided a continuous purge to prevent moisture from collecting and freezing in the components. Early in the engine development, during engine checkouts prior to the first hot-fire, the MFV was inadvertently opened. The inadvertent valve actuation was caused by leakage from the MFPV into the drain line. The drain line was undersized and the backpressure that was created opened the MFV actuator. As a result, the decision was made to isolate the fuel valve vent ports to prevent this inadvertent pressurization. In addition, the position switch cavities of the GGOV, GGFV, and OBV were also routed to their respective actuator vent lines. It was discovered that the actuator venting was sometimes activating the position switches. The switches were hermetic switches and therefore could be activated with external pressure. The plan, prior to cancellation of the program, was to isolate all of the vent lines to prevent these failures.

\section{OBV Slow Closing Due to Pusher Binding}

Post test data review of test $\mathrm{Hl}-1$, showed that the OBV had a slow closing time. The closing time was milliseconds slower than expected. The consequences of the slow closing time were minimal. Because the effects were minimal, testing continued while resolution was being worked. Subsequent tests showed closing times increasing to several, then hundreds of seconds. Review of the data revealed that the pilot 
valve was the cause of the slow response. It was suspected that there was binding between the pusher, which is made from stainless steel, and the inlet seat, which is made from vespel, at the low temperatures due to the difference between the coefficients of thermal expansion (CTE). The supplier's pilot valve design is used in many other applications, some of which are low pressure. For low-pressure applications, the pusher, loaded with a spring, provides the seat force for the ball against the vent seat while in the open position. For high pressure applications, such as the MC-1, it was determined that the actuation supply pressure provides adequate seat force and the pusher is not required. The resolution therefore was to remove the pusher and its spring from the valve.

\section{MFV Ball Seal Failure}

At engine shutdown during engine test $\mathrm{H} 1-6$, observers reported a fire at the nozzle exit post shutdown. Posttest leak checks revealed a blowing leak through the MFV. Borescope inspection of the valve while still installed on the engine revealed that the seal and its energizer spring had been expelled from its groove. The valve was removed and shipped to the supplier for failure investigation.

Valve disassembly and inspection at the supplier's facility revealed that the valve was nearly closed and the seal was pinched between the edge of the through hole of the ball and the seal groove. Witness marks on the valve body provided evidence that the energizer spring was expelled, at least, previous to the valve closing cycle. A fault tree was developed. The most probable cause identified was that of hydrodynamic force expelling the seal and energizer from its location while in a transient position. A water flow test set-up was built by the supplier within a week. The existing configuration was water flow tested, and the failure was successfully duplicated. The test was performed by pressurizing a water tank with GN2 upstream of the closed MFV. The MFV was then opened and closed while maintaining tank pressure. Valve position, upstream pressure, and downstream pressure were recorded. The first test was performed with a delta pressure of 100 psid. The pressure was increased until at approximately 350 psid, the seal failed. Interestingly, the engine Helium spin start pressure had been increased just prior to test $\mathrm{H} 1-6$ to provide faster gas generator prime time. With this change the MFV delta pressure, during engine start, changed from approximately 150 psid to approximately 320 psid.

The supplier redesigned the valve to withstand greater pressure differential. The valve supplier added a retainer ring, which was fastened to the inlet flange with lockwired screws. This ring interfaced with a groove cut into the existing seal design, positively capturing the seal. The redesign was water flow tested up to a pressure differential of 600 psid.

As mentioned previously, the valve on which this design was based was the RL10 Oxidizer Inlet Valve. The RL10 valve is a cryogenic valve, and operates at lower pressures and pressure differential than for the MC-1 application. That coupled with the fact that Teflon is approximately ten times stiffer at cryogenic temperature than at $70^{\circ} \mathrm{F}$ made the use of this seal design in the MC- 1 application unacceptable.

\section{MFV Inlet Flange Leakage}

During engine pretest leak checks, it was discovered that there was Class II external leakage at the MFV inlet flange to valve body joint. Disassembly and inspection of the valve at the supplier's facility revealed that the shim between the valve inlet flange and the valve body was deformed into the seal gland allowing leakage.

Adjustment of the ball seal preload is made by shimming between the valve inlet flange and the valve body. The shim is sandwiched between the valve inlet flange and the valve body. A Teflon jacket, springenergized seal on each side of the shim, makes the seal between the inlet flange and valve body. The shim ID is inboard of these seal glands, sandwiched, in metal-tometal contact with the valve inlet flange on one side, and the valve body on the other side, which forms a "poor seal" inboard of each gland. This "poor seal" results in a transient pressure differential across the shims as the glands pressurize at different rates as the engine pressure increases. This pressure differential, acting on the surface area of the seal gland, tends to deflect the shim into the gland that has the lowest pressure. This pressure differential resulted in yielding of the shim and subsequent leakage.

The shims were made from a soft material, Aluminum 1100-T0 which has a yield strength of $5 \mathrm{ksi}$. In addition, the shim thickness was decreased to accommodate the ball seal modification, to capture the seal, discussed previously. Analysis performed showed that a shim of thickness 0.010 inch would yield at approximately $250 \mathrm{psid}$. This problem was duplicated on the bench at the supplier's facility by pressurizing and depressurizing the valve body at approximately the same rate as during engine testing.

The following two changes were made to the design of the MFV to eliminate this problem. The two Teflon, spring-energized, face seals were replaced with 
Fluorosilicone o-rings. The Fluorosilicone o-ring acts as packing that increased the stiffness of the shim seal system. The second change made to the MFV was to select a stiffer shim material. Aluminum 6061-T6 (yield strength of $40 \mathrm{ksi}$ ) was selected for the new shim material.

\section{GGFV Seat Failure}

At engine shutdown during engine test H3-1A, observers reported a fire at the nozzle exit post shutdown. Posttest leak checks revealed GGFV internal leakage. Valve disassembly and inspection at the supplier's facility revealed that the seat seal was displaced from its gland. The energizer spring was expelled into the cup of the outlet poppet.

A fault tree was developed. The most probable cause was expulsion of the seal from its gland by the engine transient pressure differential, similar to the MFV ball seal failure. Water flow tests, similar to those performed for the MFV ball seal failure, were performed using the same facility. Again, the failure was duplicated.

A new seal configuration was developed. A solid Teflon seat was designed. The solid seat design was tested and found to perform well at ambient temperatures at MC-1 operational pressures.

The cause of the seal failure was also attributed to the greater ductility of Teflon at ambient temperatures. The energized seal employed on the GGFV was originally designed for use at cryogenic temperatures.

Because of the uncertainty of the operational environments for the GGOV on succeeding MC-1 tests, the GGOV temperature was uncertain. This caused concern that a failure similar to the GGFV could occur on a GGOV. Therefore, the solid seal design was incorporated into the GGOV. Because the OBV is adequately chilled prior to engine start, this same concern did not exist and did not require the added strength of the solid seal.

\section{Slow Pilot Valve Response Due to Grease}

Engine pretest checkouts, before its first cold box test, were performed and all valve responses were within the nominal ranges. The pretest checkouts were performed at ambient temperature of approximately $70^{\circ} \mathrm{F}$. The cold box was then activated to obtain ambient air conditions of approximately $-25^{\circ} \mathrm{F}$ around the engine. The temperature was held for several hours prior to hotfire. At engine start the MOV and OBV responses were slow. The limit switch data did not show $O B V$ valve movement until nearly 60 seconds and MOV movement for 2 seconds.

Evaluation of the test data revealed that the pilot valves were the most likely causes of the problems. A series of response time tests at varying temperatures were performed on the pilot valves at the supplier's facility. The slow response times were duplicated. Disassembly and inspection revealed that the pilot valve had lubricant on some of the sliding parts. Interviews with the sub vendor's assembly personnel revealed that lubricant was used as an assembly aid. Therefore the cause of the problem was identified as the uncontrolled application of an uncontrolled lubricant to the assembly. This lubricant then froze or stiffened, resulting in slow response of the pilot valve. Parts were cleaned and drawings changed to preclude the use of any grease.

During this investigation it was also discovered that the pilot valve was leaking in excess of the specification requirement at temperatures below approximately 120F. The main valve supplier requirement for pilot valve temperature operating range was $140 \mathrm{~F}$ to $-100 \mathrm{~F}$. This was a derived requirement from the MSFC specification which stated a $-65 \mathrm{~F}$ ambient environment and a 6 minute LOX chill through the OBV. During engine testing, LOX chill times were as long as 2 hours, allowing the pilot valve temperatures to reach approximately $-180 \mathrm{~F}$. The leakage was attributed to the static seals within the pilot valve and the static seals between the solenoid cartridge and the main valve supplier's manifold. The "girth" seal between the cartridge and the manifold is the primary suspect as this seal must be stretched over the cartridge OD to fit into its gland. This could not be verified by test because each seal cannot be isolated. It was suspected that this seal is damaged during the stretching procedure. As a result, a redesign effort was initiated to accommodate the new pilot valve temperature requirements. These new temperature requirements also drove changes to the verification and acceptance test procedures.

A number of redesigns were considered and tested. The approach was to maintain the pilot valve basic design and, included configuration changes, elimination of the cartridge-manifold interface, and seal material changes. Test results were not promising. Leakage rates were either high or sensitive to assembly/disassembly. The decision was made to simply off-mount the pilot valves from the GGOV and OBV, which were the only valves that approached pilot temperatures of $-150 \mathrm{~F}$. Of course modifications would be required for the engine assembly, but there would be minimal impact to the pilot valve design. The modification to off-mount the pilots was not approved prior to program cancellation. 


\section{Slow IFV Response Due to Grease}

Engine tests H4-2, H4-3, and H4-4b were conducted with an enclosure around the engine that was chilled with LN2 to obtain ambient conditions of approximately $-25 \mathrm{Deg} F$ around the engine. The temperature was held for several hours prior to ignition. During engine start, the IFV current trace showed an open response time ranging from approximately 425 to $565 \mathrm{msec}$ on the three tests. Previous engine hot-fires utilizing these valves had response trmes ranging from 175 to $280 \mathrm{msec}$.

Three IFV's were chilled and tested at the supplier's facility for response time. All response times were slow. The cause for the slow response was the use of Krytox 240AC grease, which was freezing at the lower temperatures. Corrective action included changing from Krytox $240 \mathrm{AC}$ to Braycote 601 .

In addition, engine test data revealed that the hypergol flow rate could be reduced. This meant that the flow coefficient for the IFV could be reduced. Therefore, the coil/armature gap was reduced to provide increased pull-in force.

MFV Leakage at Low Pressure Due to Application of Backpressure

During engine pretest leak checks, it was discovered that the MFV was leaking internally such that the fuel system could not be pressurized. The valve was removed and returned to the supplier for investigation. The as-received leak checks at the supplier's facility showed no leakage. The valve was then returned to the engine for installation to verify the leakage measured. The valve again had a blowing leak. The valve was again returned to the supplier. This time the leak check was performed at a low pressure, 5 psid, and the leakage was repeated.

Disassembly and inspection revealed that the ball seal had zero preload. A fault tree was developed. It was suspected that reverse pressure resulted in yielding of the ball seal energizer spring. The main ball seal has an internal spring, which upon valve assembly is compressed to give a preload of the seal on the ball. When reverse pressure is applied to the valve, the Teflon jacket can squeeze the internal spring. When pressure is high enough, the spring will take a permanent set. All preload by the seal on the ball is then lost. The valve will leak at low pressures but seal at high pressures. Tests were performed where 50 psig and $250 \mathrm{psig}$ back pressure was applied to the seal. The 50 psig back-pressure resulted in little loss of preload.
The 250 psig back-pressure resulted in a significant loss of preload.

Review of engine operations revealed that during engine leak checks the MFV is back pressurized to 35 psid. Relief valve settings, to prevent throat plug failure, are below $50 \mathrm{psig}$. The cause of the back pressure was never identified.

\section{$\underline{\text { OBV Seat Fracture }}$}

Post-test R2-1A engine leak checks revealed a blowing internal seat leakage of the OBV. Data review revealed that that the OBV was leaking at engine start. The Gas Generator was starved for LOX because of the blowing leak through the OBV.

The valve was sent to the supplier's facility for failure investigation. After disassembly, examination of the seal showed a crack through the Teflon jacket with the spring intact and in place. The valve seat showed no apparent damage. Additionally during valve disassembly, marks and included particles were discovered on the inlet plunger. The included particles were determined to be composed primarily of aluminum. Investigation into the origin of the inclusions and marks on the inlet plunger were progressing at the time of program cancellation.

Examination of the seal continued at MSFC where an Environmental Scanning Electron Microscope (ESEM) could be employed and material properties could be determined. ESEM showed no material inconsistency at the crack. The seal was examined with an optical microscope, which showed porosity in the Teflon at the break.

The specification on supplier's source control drawing controlled the Teflon as raw material. Under this spec, three samples out of a lot of Teflon are tested for porosity. A corrective action for this problem was being worked at program cancellation. The proposed corrective action included a density or specific gravity test, of the machined Teflon part.

\section{Bellows Free Length Set and Spring Rate}

As part of an $\mathrm{OBV}$ seat leakage investigation, the valve was disassembled and the bellows length and spring rate were measured. The spring rate of both bellows, were higher than specified by the valve supplier's drawings. Both bellows had taken a permanent set in the valve open direction. This particular OBV was a high cycle valve. This condition was discovered on other poppet valves. 
Several meetings, attended by the bellows supplier, valve supplier, and MSFC, were held to gain an understanding of the nature of the bellows as manufactured and over time with use. The bellows supplier reported the permanent set was not an unexpected occurrence. Rather, it should be considered in the design of a bellows. At the time of program cancellation, work on this issue was continuing.

\section{$\underline{\text { Summary of Lessons Learned }}$}

Engine valves provided a considerable share of the problems encountered during the engine test phase of the program. As a result, there were a number of lessons learned during the valve development that may be of some value. The following sections will attempt to cover these lessons learned.

\section{Contract Type}

Because the valves were procured under the premise that existing designs would be used, and that design and development would be fairly straightforward, a fixed price contract was used. The use of a fixed price contract proved to be a significant mistake. In something as complex as an engine development program, there exists too many unknowns to use a fixed price contract. As the engine is developed, valve requirements are likely to change. If requirements change, a contract modification will be required. It then becomes very difficult to assess the impact of the new requirement. For this reason alone, a fixed price contract is not acceptable. Also, when writing the procurement specification, it is unlikely that the verification and acceptance test requirements will be known because the design details are unknown. Changes to the acceptance and verification test requirements also require a contract modification. Failure analysis, determination of corrective actions, and associated testing proved to be very difficult under a fixed price contract. For example, one of the contract modifications had 22 items or tasks identified to resolve a problem. The final resolution of the problem was significantly different from what was originally planned. In the end, some of the original 22 tasks were performed, some were not performed either because they were not required with the new approach or they simply had not completed the task. Needless to say the next contract modification was even more complex.

If $\underline{\text { any }}$ development is required, a fixed price contract is not the best means for procuring a valve. In development of an engine, because requirements typically are not fully defined, or may change, valves should not be procured under a fixed price contract.

\section{The Fifteen Percent Rule-of-Thumb}

As discussed previously, the propellant valves were procured under the premise that existing designs would be used to minimize development and testing requirements, and therefore cost and schedule. The original design point of the existing valve must be known. Some use a rule-of-thumb that if the design point of the new application is more than $15 \%$ greater or less than the original design point, then significant redesign or development is required. For example, one of the problem areas on the MC- 1 valves was the ball seal design. The MOV and MFV were derivatives of the RL10 Oxidizer Inlet Valve (OIV). Because seat design is a large portion of a valve's development cost, it was believed that by using the OIV seat design, a large savings would be recognized. The MFV and MOV operating pressures were greater (by more than $15 \%$ ), and the pressure differentials were greater (by more than $15 \%$ ) than the OIV design points. Even more obvious and embarrassing was the fact that the MFV seal was at ambient temperature, while the OIV design point was cryogenic temperature. In sealing applications, it is typical to assume that cryogenic temperature is the worst case. However, what was neglected was the fact that Teflon stiffness at cryogenic temperature is ten times that at $70^{\circ} \mathrm{F}$, and the potential for seal structural failure is more probable at the higher temperature. If the $15 \%$ rule had been considered for all requirements, a potential problem would have been more likely identified. Despite these large differences, the OIV development testing of the seat design was heavily relied upon. Engine testing revealed the errors in this approach.

When considering buying an existing design, one must know the nominal design points for that design, then compare the new application's requirements to those original design points. If the $15 \%$ rule is violated, assess how it impacts the function of critical elements of the component. If the $15 \%$ rule is violated, this should alert one to address those areas early in the project.

\section{Development Testing}

Because of the short schedule and tight budget, it was agreed that some of the valve development testing, normally performed, would be eliminated. It was understood that some problems would occur as a result of this decision and that those problems would be worked during engine development. This approach, again, proved to be a flawed. The most obvious example of this was the problem associated with seal failures. During development of the specifications, 
flow testing was not specified to reduce cost and delivery schedule. As mentioned above, during the failure investigation, the first task performed was a flow test. It was quickly recognized that the seal design was not acceptable. The time required to set-up and perform the test was approximately one week. One week would have been insignificant during the valve development but discovery of the problem during the engine testing phase resulted in significant costs.

Test at the component level early in the development. The cost of finding design shortcomings during the engine development phase will most likely exceed that of performing the test early at the component level.

\section{Acceptance Testing}

Another problem revealed during engine testing was that the acceptance testing was not screening all hardware problems. For example, there were a number of problems with inappropriate grease applied to valves. Review of the acceptance test procedure revealed that in some cases, the valve response was not being measured at the low temperature requirement. In addition, appropriate measurements must be taken to verify that the worst case environment is indeed simulated. Acceptance testing is performed to screen hardware for quality escapes.

Acceptance testing should be performed at worst case conditions. Not testing at the worst case conditions will allow some quality escapes to pass through the system only to be discovered, at a high cost, at the engine level.

\section{$\underline{\text { Spares }}$}

Again, in an effort to minimize cost, neither spare valves nor spare piece parts were procured. This obviously proved to be a problem especially during the engine test phase. The problems experienced during the engine test phase and the lack of spare hardware made logistics of providing valves for engines difficult. Engines were continuously cannibalized to provide valves to the engine currently being tested. Frequently the engine testing was delayed while valves were being transported and modified.

The lack of spare valves or development valves also hindered engine development and failure investigations. Some testing at the component level could have been performed at MSFC, but hardware was not procured to support that effort.

Another thing to consider is that during the engine development phase, the specified life of components will likely be exceeded. During engine testing, the cycle life on valves exceeded the specified cycle life. One way to deal with this is to procure enough valves so that when the cycle life is exceeded, they are simply replaced. Another more feasible approach may be to identify, early in the project, life limited parts and replace those parts at appropriate intervals.

Spares should be specified and procured at the beginning of the program to minimize the logistical problems during the engine development phase.

\section{Engine Flight vs. Development Requirements}

Some of the engine flight requirements may be different from the development requirements. Obviously some of the environments, thermal and vibration for example, will be different, but consider also any operational requirements. The specifications for the valves included the flight requirements for the duration of engine conditioning, which was specified as six minutes. Therefore, the supplier's analysis predicted the pilot valve minimum temperature to be $-100^{\circ} \mathrm{F}$, based on a six minute engine conditioning period. However, during engine development testing the duration of the engine conditioning typically lasted for hours. As a result, the pilot valves reached $-180^{\circ} \mathrm{F}$. In this case, failure to consider longer durations for engine conditioning resulted in pilot valve leakage problems. $\mathrm{Had}$ the requirement for longer durations of engine conditioning been specified, the supplier would have proposed a different design, most likely to off-mount the pilot valves.

Both the engine development operational requirements as well as flight operational requirements must be considered.

\section{$\underline{\text { Range Safety }}$}

Range safety requirements were not addressed until late in the program. At that time, the decision was made to add new requirements for some of the engine valves. Some of the engine valves were to become part of the flight termination system (FTS). The FTS requirements had serious impacts on the valve designs. The flight ranges specify requirements such as structural safety factors, margin on thermal environments, margin on vibration test requirements, acceleration requirements, acceptance vibration, and acceptance thermal cycling to name a few.

Range safety requirements should be addressed early and incorporated into the procurement specifications.

\section{$\underline{\text { Reverse Pressure }}$}


The MC-1 valve specifications did not address application of reverse pressure on the valve. In this case, application of reverse pressure on the engine did not result in damage. During routine engine leak checks, 35 psig is applied downstream of the valve. It was later discovered that the ball seal might be damaged with application of 50 psig reverse pressure.

Consider the potential for reverse pressure on the valve from either engine checkout operations, engine operation, or component testing. The capability or limitation of the design due to reverse pressure should be identified early in the project.

\section{Weep Holes and Vents}

Initially, the actuator vent lines were routed to a common drain line so that one line each for fuel and LOX would carry all fluids outside of the aft compartment. In addition, a purge barrier was maintained in the LOX drain to prevent moisture from entering the specific areas on the engine including valves. This was done to prevent moisture from freezing within the pilot valves. Initially, the MC-1 drain line was so undersized that leakage into the drain system resulted in inadvertent valve actuation. The decision was made to isolate the actuator vent ports. However, some design solution was required to prevent contamination from entering through these vent lines.

Some of the valves procured had weep holes and vents in the valve body open to the atmosphere. Although this did not result in any problems, the potential existed. The component will be exposed to rain on the test stand and in transit, in different orientations. With any open holes, the potential for getting rain water in the valve and later freezing exists.

Design of the vent and drain system should not be overlooked. Detailed system analysis must be performed to assure that leaking or venting components that are routed to a common drain line do not negatively interact with other components. Assure that vents and drains are specified to be designed to prevent contamination from entering the system.

\section{Instrumentation Interface Requirements}

Review of engine test data sometimes showed anomalous position switch data. Discussions with the switch vendors revealed that, although the switches are hermetic, some oxidation of the contacts does occur and that some minimum current is required to clean the contacts.
The valve specification should provide the instrumentation interface requirements.

\section{Leakage Measurement}

On one occasion, the valve passed the acceptance test and was delivered to the test stand. During engine leak checks, the data revealed that the valve just installed, had a blowing leak. It was discovered, during the acceptance testing the pressure was applied rapidly and therefore seated the pressure-energized seal. During the engine level leak checks, because of the large volumes, the pressure increases at a slower rate. The valve did not have adequate pressure to energize the seal.

Acceptance tests should be performed to simulate the same conditions as the engine level checkouts, as well as the engine operating conditions. For example, if pressure energized seals are employed, part of the acceptance test at the supplier's facility should be a leak check at a very low pressure as well as the engine checkout pressure. This will capture valve discrepancies prior to installation and allow a direct comparison between the acceptance test data and the engine level checkout data.

\section{Acknowledgments}

Special thanks to Mr. Richard Sheller, Sr. Engineer, Sverdrup Technology, Huntsville, Alabama and Mr. Kevin Ward, MSFC, TD62, for their review and inputs. 